\title{
HIV/AIDS-related stigma and HIV test uptake in Ghana: evidence from the 2008 Demographic and Health Survey
}

\author{
Jacob Novignon ${ }^{a}$, Nicholas Novignon ${ }^{b}$, Genevieve Aryeetey ${ }^{c}$ and Justice Nonvignon ${ }^{c}$ \\ a Department of Economics, University of Ibadan, Ibadan, Nigeria. \\ Email: nonjake@gmail.com \\ ${ }^{b}$ Ghana Education Service, Ga West Municipal Education Directorate (Methodist Education Unit - \\ Pokuase Methodist Basic School), Amasaman, Ghana \\ Email: nnovignon@gmail.com \\ ${ }^{c}$ Department of Health Policy, Planning and Management, School of Public Health, University of \\ Ghana, Legon, Ghana. \\ Email: gcaryeetey@ug.edu.gh; Email: jnonvignon@ug.edu.gh
}

\begin{abstract}
The study examined the association between HIV test uptake and socioeconomic characteristics of individuals, including HIV-related stigma behaviours. The study also investigated the socioeconomic determinants of HIV-related stigma in Ghana. Cross tabulations and logistic regression techniques were applied to data from the 2008 Ghana Demographic and Health Survey. The results showed significantly low HIV test uptake and some level of HIV-related stigma prevalence in Ghana. Higher wealth status, educational attainment and HIV-related stigma were significant determinants of HIV test uptake. Aside wealth status and education, rural place of residence and religious affiliation were positive and significant determinants of HIV-related stigma. The findings call for comprehensive HIV education including treatment, prevention and care. Legislations to discourage stigma and improve HIV-testing will be critical policy steps in the right direction.
\end{abstract}

Keywords: HIV/AIDS, Stigma, HIV test uptake, Logistic regression, Ghana

\section{Résumé}

L'étude a examiné l'association entre la participation au test du VIH/SIDA et les caractéristiques socioéconomiques des individus, y compris les comportements de stigmatisation liées au VIH/SIDA. L'étude a également étudié les déterminants socioéconomiques de la stigmatisation liée au VIH/SIDA au Ghana. Les tableaux croisés et la technique de régression logistique ont été appliquées aux données de l'enquête démographique et de la santé du Ghana réalisée en 2008. Les résultats ont montré une très faible participation au test du VIH/SIDA et un certain niveau de prévalence de la stigmatisation liée au VIH/SIDA au Ghana. Les individus les plus riches, les individus avec le niveau d'éducation supérieur et de la stigmatisation liée au VIH/SIDA sont des déterminants significatifs de la participation au test du VIH/SIDA. Outre, des niveaux de richesse et d'éducation, le lieu de résidence en milieu rural et l'appartenance religieuse sont des facteurs déterminants positifs et significatifs de la stigmatisation liée au VIH/SIDA. Les conclusions appellent à la sensibilisation globale sur le $\mathrm{VIH}$, son traitement et sa prévention. Les législations visant à décourager la stigmatisation et à améliorer le dépistage du VIH/SIDA constitueront des étapes essentielles dans les politiques de recommandation publiques.

Mots clés: VIH/SIDA, la stigmatisation, l'adoption du test du VIH/SIDA, régression logistique, Ghana 


\section{Background}

Seeking early treatment for HIV and AIDS is crucial for the reduction in incidence and spread of the epidemic. This has led to the emergence of the test and treat paradigm which has received massive support from researchers and policy makers alike. In this regard the Ghana AIDS commission (GAC), like many other AIDS control institutions, has made HIV testing and counselling a major policy focus. While the importance of such policies cannot be over emphasised, several social and economic factors may hinder its successes in terms of achievements.

A major threat to the promotion and improvement of HIV test uptake is stigmatization. HIVrelated stigma may be pervasive and discriminating hence a harmful effect on prevention and treatment responses. People living with HIV/AIDS (PLWHA) have usually suffered from stigma from both family members and communities. Goffman (1963) defined stigma as a mark that links a person to undesirable characteristics. HIV-related stigma and discrimination ranges from a simple gossip to outright discrimination, resulting in job loss, house eviction, rejection, isolation and even killing of PLWHA (Ulasi et al., 2009). Koku (20II) noted two forms of stigma; first is an 'enacted' or 'experienced' stigma which involves directly experiencing some form of rejection, discrimination or abuse as a result of stigma. The second is the 'perceived' or 'felt' stigma which considers fears about enacted stigma.

Efforts have been made to reduce the spread of HIV/AIDS and to provide treatment for infected individuals in Ghana, notable among which include the establishment of the Ghana AIDS Commission in 200I. In response, the prevalence of HIV/AIDS seems to be on a downward trend from $3.6 \%$ in 2003 , to $2.7 \%$ in 2005 . This increased to $3.2 \%$ in 2006 and eventually an estimate of $1.3 \%$ was reported for 2013. The prevalence rate also varies across various regions with the Northern and Upper West Regions having the lowest rate of prevalence $(0.8 \%)$ and the Eastern region having the highest (3.7\%). Prevalence was also highest in 45-49 year group (3.3\%) and lowest in 15-19 year group (0.8\%) (Ghana AIDS Commission, 2013).

People Living with HIV/AIDS (PLWHA) continue to suffer from stigma and discrimination in developing regions where knowledge and understanding of the epidemic is relatively low. The impact of stigmatization and discrimination in the fight against the HIV/AIDS epidemic has resulted in some analysts referring to it as the 'silent killer'. HIV-related stigma hampers the effective response, deters people from knowing their status, prevents high risk individuals from receiving needed services, increases risky sexual behaviour due to rejection and isolation and creates non-compliance with breastfeeding recommendations for HIV positive mothers. Thus, halting the epidemic requires comprehensive efforts, including changing the perception of individuals towards HIV and PLWHA (WHO, 2004).

In this regard, the current study sought to examine the determinants of HIV-related stigma and evaluate the impact of HIV-related stigma on HIV test uptake in Ghana. The study also examines other socio-economic determinants of HIV test uptake, including education levels, sexual behaviour and wealth status.

\section{Review of existing literature}

HIV-related stigma in Ghana is not different from many other countries in the sub-Sahara Africa region where individuals are largely conservative and HIV infections are solely attributed to sexual immorality or immoral behaviours; PLWHA are considered to be promiscuous or prostitutes who are being punished for their sins. Some researchers have argued that cultural values against prostitution, promiscuity and homosexuality may be the source of HIV/AIDSrelated stigma in Ghana (Ankomah, 1998, Mill, 2003). Koku (20I I) provided evidence to show that there exists significant but negative association between risky sexual behaviour and HIV testing among females in communities with high stigma levels. Mill (2003) also showed that many HIV positive women in Accra and Agomanya felt the need to keep their HIV status to themselves to avoid perceived shame and disgrace from the community.

Factors that influence HIV-related stigma and discrimination have been broadly identified to be social and economic. For instance, Ulasi et al. (2009) used data from four sub-districts in Kumasi, Ghana to assess HIV/AIDS related stigma and discrimination of PLWHA. The authors used four stigma constructs, employment-based discrimination, screening and identification of PLWHA, revelation of HIV status and social contact. The results showed that high education, religion, gender and employment status were significant determinants of HIV-related stigma. Awusabo-Asare and Marfo (1997) found that HIVrelated stigma and discriminatory practices were prevalent among health care professionals in Ghana. These included refusal to treat PLWHA, refusal to work in HIV/AIDS facilities, maltreatment of PLWHA and inequality in treatment between HIV infected and uninfected patients. Though there have 
been improvements in the behaviour of health workers towards PLWHA in recent times, more still needs to be done to eliminate it.

Using a sample of 324 students from Ghana, Asante (2013) found that respondents who were never married, younger and had knowledge of HIV transmission were more likely to test for HIV. Male respondents were also more likely to have HIV test, relative to their female counterparts. Similarly, Maughan-Brown and Nyblade (2013) provided evidence from South Africa to show that black women who reported stigmatizing behaviour were more likely to test for HIV. The study also showed that perceived stigma and observed-enacted stigma significantly reduced the odds $(0.6 \mathrm{I}$ and 0.42 , respectively) of women testing for HIV. In other empirical evidence, Sambisa (2008) found that lack of access to testing facilities and fear of test results limited test uptake among men and women in Zimbabwe. Aside observed-enacted stigma, education, religion, mass media exposure, HIV risk and condom use influenced HIV test uptake. Wong (20I3) also provided evidence from Malaysia to show that, among other things, low risk perception constituted a major barrier to HIV testing.

Some studies have also established association between socio-economic factors and HIV-test uptake. For instance, in analysing the predictors of HIV testing uptake among tuberculosis patients in North Western Ethiopia, Ayenew et al (2010) found that formal education, high awareness about benefits of HIV testing and counselling and low stigmatized attitude associates positively with HIV test uptake.
Myerson et al. (2012) provided evidence from south India that HIV testing and counselling (HTC) was associated with condom uptake among HIV positive and negative men and women. The authors also found no significant association between number of sexual partners and counselling completeness. Similarly, Helleringer et al. (2009) showed that individuals from households in the lowest income quintile were significantly less likely to have ever used facility-based HTC, relative to home-based HTC. They also found no association between socio-economic status and home-based HTC uptake.

While the above studies separately analyse the determinants of HIV-related stigma and HIV test uptake, the exact relationship between HIV-related stigma and HIV test uptake was not examined. The current study sought to provide new evidence from Ghana.

\section{Brief conceptual framework}

Figure I presents a conceptual framework on the link between HIV-related stigma and HIV test uptake. The figure suggests a direct effect of the environment on HIV test uptake and an indirect link through HIV-related stigma. The environment in which an agent (individual, family etc) lives may shape the behaviour (including HIV-related stigma) of the agent which may influence the willingness to test for HIV . While three categories of stigma are depicted in the figure, only perceived stigma is used in the analysis of the current study. Other measures of stigma were not available in the dataset. 


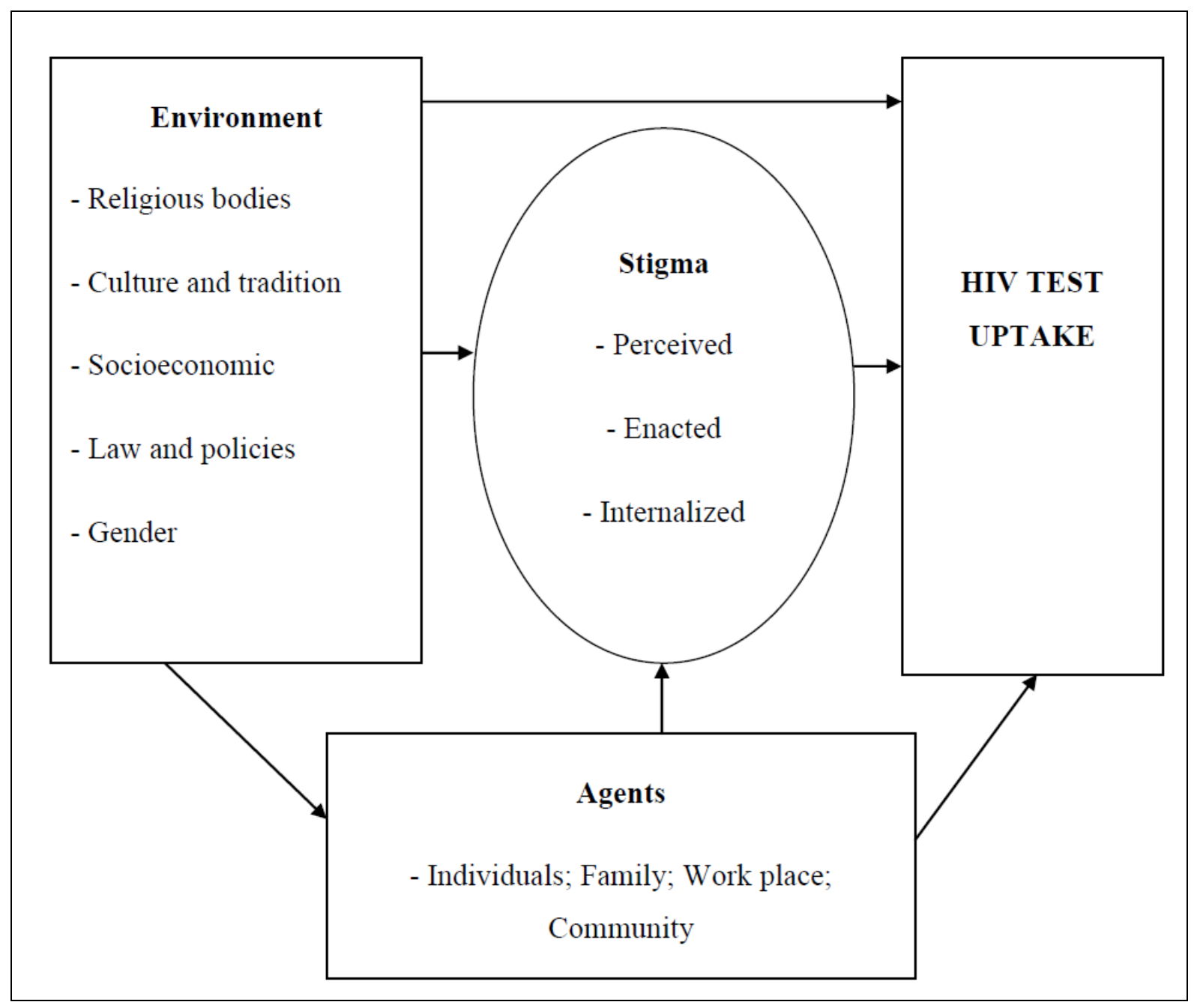

Figure I: HIV-related stigma and HIV test uptake

\section{Methods}

Data used in the current study was sourced from the 2008 Ghana Demographic and Health Survey (GDHS). The 2008 GDHS is the fifth in a series of national-level population and health surveys conducted in Ghana as part of the global demographic and health surveys (DHS) programme. The 2008 survey was designed to provide information to monitor the population and health situation in Ghana (Ghana Statistical Service, 2008). The DHS is a comprehensive data set collected by Macro International in collaboration with National statistical services in various countries. In Ghana, the 2008 GDHS was conducted by the Ghana Statistical Service (GSS) in collaboration with the Ghana Health Service with technical support from ICF Macro through the MEASURE DHS programme. The 2008 GDHS data was collected on individuals and households and covers mostly health and demographic characteristics of respondents. Information collected include socioeconomic, demographic, sexually transmitted infections, HIV testing, knowledge and stigma, sexual behaviour etc.
Sampling was conducted in two stages and this was based on the 2000 Population and Housing Census to produce separate estimates for key indicators for each of the 10 regions in Ghana. A sample of more than 12,000 households was selected in the second stage. Each household selected was eligible for interview with a household questionnaire and a total of II,778 households were finally interviewed. All eligible men between the ages of 15-59 and women between 15-49 years were interviewed in about half of the households using the Women's and Men's questionnaires respectively. A total of 4,916 women and 4,568 men from 6,14I households were interviewed (Ghana Statistical Service, 2008).

The final sample included in the study was restricted to 1635 men between the ages of 15-59 and 1676 women between 15-49 years who have been sexually active in the past 12 months.

\section{Variables}

Two separate dependent variables were used in the study, since analysis was conducted in two stages. The first was a measure of stigma, measured by three different variables that suggest that individuals 
were more of less inclined to stigmatize. The variables include whether respondents were willing to take care of relatives with HIV; whether they will allow an HIV positive person to continue teaching and finally, whether they will patronize a vendor infected with HIV. The variables were coded as I if the response to any of the questions was YES and 0 if response was NO. The second dependent variable was whether respondents have ever tested for HIV with codes of 0 and $I$ if response was NO and YES, respectively.

The independent variables included in the analysis are presented and described in Table I. They range from socioeconomic, demographic and sexual behaviour variables. It must be noted that in the second regression analysis of determinants of HIV test uptake, the stigma variables were employed as independent variables.

Table I: Description of independent variables

\begin{tabular}{|c|c|}
\hline Variable & Description \\
\hline Education & $\begin{array}{l}\text { Highest education level of respondent presented in categories; No education, Primary, sec- } \\
\text { ondary and higher }\end{array}$ \\
\hline Residence & $\begin{array}{l}\text { A dummy variable that captures the place of residence of respondent coded as } 0 \text { if rural and } \\
\text { I if urban }\end{array}$ \\
\hline $\begin{array}{l}\text { Wealth quin- } \\
\text { tiles }\end{array}$ & $\begin{array}{l}\text { Shows the economic situation of the respondents' household with categories, poorest, poor, } \\
\text { middle, rich and richest }\end{array}$ \\
\hline Employment & $\begin{array}{l}\text { A dummy variable that captures whether the respondent is currently engaged in any form of } \\
\text { economic activity }\end{array}$ \\
\hline Condom use & $\begin{array}{l}\text { A dummy variable that captures whether the respondent used a condom during the last } \\
\text { sexual activity }\end{array}$ \\
\hline Alcohol use & $\begin{array}{l}\text { A dummy variable that captures whether the respondent took any form of alcohol during } \\
\text { the last sexual activity }\end{array}$ \\
\hline Age & Age of respondent in years \\
\hline $\begin{array}{l}\text { Ever heard } \\
\text { AIDS }\end{array}$ & A dummy variable on the knowledge of respondents on HIV/AIDS \\
\hline Test place & A dummy variable that shows whether the respondent knows a place for HIV test \\
\hline Religion & $\begin{array}{l}\text { A categorical variable that captures the religious affiliation of respondents. The categories } \\
\text { include no religion, Christian, Muslim and traditional/spiritual }\end{array}$ \\
\hline
\end{tabular}

Source: Authors' compilation

\section{Empirical technique}

Three different strategies were used in the empirical analysis of the study. First, a univariate analysis was conducted to present the descriptive statistics of the variables included in the study. The numbers and percentages of these variables were reported in the analysis. The second analysis made use of bivariate techniques to establish association between the explanatory variables and outcome variable (HIV test uptake). This analysis also reported numbers and percentages from cross tabulations with chi- square test statistics and probability values to show the statistical significance of association.

The third analysis made use of logistic regression technique to predict the odds ratios and statistical significance of association in a multivariate framework. The multivariate logistic model was conducted for the determinants of HIV-related stigma and the determinants of HIV test uptake, including variables like HIV-related stigma and other socioeconomic characteristics of respondents. All analysis was conducted separately for male and female respondents. 


\section{Results}

Table 2 shows descriptive statistics for all the variables included in the analysis. The numbers and proportions of the variables are presented for both male and female respondents. Statistics on the key variables of interest are also presented in Table 2.

A majority of respondents were resident in rural areas (about $63.9 \%$ of women and $64.1 \%$ of men). About $29 \%$ of both men and women were in the poorest quintile, relative to about $18 \%$ in the richest wealth quintile. Again, about $51 \%$ of male respondents had at least secondary education, relative to $37 \%$ of female respondents. Significant proportion of female respondents (39\%) had no formal education, relative to about $28 \%$ of male respondents. A significant proportion of male and female respondents were Christians.

The statistics on HIV/AIDS test uptake and knowledge show that, while significantly high proportions of both men and women in their reproductive age had heard of HIV/AIDS and know where to test for the disease in Ghana, significantly low proportions of respondents had ever tested for the disease. Also about $69.3 \%$ and $76.6 \%$ of women and men, respectively, know a place to test for HIV/AIDS. However, only $26.2 \%$ and $16.8 \%$ of women and men, respectively, have ever been tested for HIV/AIDS.

In terms of HIV-related stigma and discrimination behaviour, the statistics show that the level of stigma depends on the type of behaviour individuals are inclined to exhibit towards people living with HIV/AIDS. For instance a higher proportion of respondents $(74.2 \%$ women and $80.3 \%$ men) were willing to take care of a relative with HIV/AIDS. Similarly, majority of the respondents were inclined to allow a person with HIV/AIDS to continue teaching. A contrary observation was made when respondents were asked if they would buy from a vendor with HIV/AIDS. Higher proportion of men $(59.7 \%)$ and women $(73.1 \%)$ were inclined to stop buying from a vendor with HIV/AIDS. While the former variables suggest low HIV-related stigma behaviour, the later showed high stigma behaviour.

Table 2: Univariate analysis of characteristics of respondents

\begin{tabular}{|c|c|c|}
\hline Variable & $\begin{array}{c}\text { Female } \\
(\%)\end{array}$ & $\begin{array}{c}\text { Male } \\
(\%)\end{array}$ \\
\hline \multicolumn{3}{|c|}{ HIV/AIDS test uptake and knowledge } \\
\hline \multicolumn{3}{|c|}{ Ever tested for HIV/AIDS } \\
\hline No & $\mathrm{I}, 198(73.8 \mathrm{I})$ & $1412(83.16)$ \\
\hline Yes & $425(26.19)$ & $286(16.84)$ \\
\hline \multicolumn{3}{|c|}{ Know a place to get AIDS test } \\
\hline No & $498(30.68)$ & $397(23.38)$ \\
\hline Yes & I I 25 (69.32) & $130 \mid(76.62)$ \\
\hline \multicolumn{3}{|c|}{ Perceived HIV-related Stigmatization and discrimination } \\
\hline \multicolumn{3}{|c|}{ Willing to care for relative with AIDS } \\
\hline No & $395(24.34)$ & $309(18.20)$ \\
\hline Yes & $1204(74.18)$ & 1363 (80.27) \\
\hline \multicolumn{3}{|c|}{ Person with AIDS allowed to continue teaching } \\
\hline No & $604(37.22)$ & $580(34.16)$ \\
\hline Yes & $986(60.75)$ & $1080(63.60)$ \\
\hline \multicolumn{3}{|c|}{ Would buy vegetables from vendor with AIDS } \\
\hline No & I I $87(73.14)$ & $1014(59.72)$ \\
\hline Yes & $424(26.12)$ & $662(38.99)$ \\
\hline \multicolumn{3}{|c|}{ Risky sexual activities } \\
\hline \multicolumn{3}{|c|}{ Used condom at last intercourse } \\
\hline No & | 485 (96.8I) & 1466 (92.38) \\
\hline Yes & $49(3.19)$ & $121(7.62)$ \\
\hline \multicolumn{3}{|c|}{ Consumed alcohol last time had sex } \\
\hline No & | 394 (90.87) & | 428 (89.98) \\
\hline Yes & $140(9.13)$ & $159(10.02)$ \\
\hline \multicolumn{3}{|c|}{ Partner has other wives } \\
\hline No & $1390(82.94)$ & \\
\hline
\end{tabular}


Yes

Respondent currently working
No
Yes
Type of place of residence
Rural
Urban
Wealth Index Quintile
Poorest
Poor
Middle
Rich
Richest
Age group
I5-19
$20-24$
$25-29$
$30-34$
$35-39$
$40-44$
$45-49$
$50-54$
$55-59$

Highest Educational level of respondent

No education

Primary

Secondary

Higher

Religion

No religion

Christian

Muslim

Traditional/Spiritual

Administrative region

Western

Central

Greater Accra

Volta

Eastern

Ashanti

Brong Ahafo

Northern

Upper East

Upper West
$286(17.06)$

$182(10.86)$

$1494(89.14)$

32 (1.87)

$1675(98.13)$

$1072(63.96)$

1094 (64.09)

604 (36.04)

$613(35.91)$

$486(29.00)$

345 (20.58)

245 (14.62)

$299(17.84)$

301 (17.96)

500 (29.29)

$347(20.33)$

$251(14.70)$

$306(17.93)$

303 (17.75)

48 (2.86)

259 (15.45)

$362(21.60)$

331 (19.75)

302 (18.02)

$210(12.53)$

164 (9.79)

$$
\begin{gathered}
4(0.23) \\
70(4.10) \\
210(12.30) \\
300(17.57) \\
326(19.10) \\
274(16.05) \\
250(14.65) \\
185(10.84) \\
88(5.16)
\end{gathered}
$$

66I (38.72)

364 (21.32)

63I (36.97)

51 (2.99)

479 (28.06)

218 (12.77)

875 (51.26)

135 (7.91)

62 (3.84)

$1119(69.29)$

102 (6.24)

1021 (62.45)

328 (20.06)

I84 (II.25)

137 (8.48)

$178(10.89)$

174 (10.77)

$83(5.08)$

$86(5.33)$

191 (II.83)

$179(10.95)$

137 (8.48)

146 (8.93)

161 (9.97)

$156(9.54)$

$210(13.00)$

222 (13.58)

133 (8.24)

135 (8.26)

209 (12.78)

207 (I2.82)

$153(9.36)$

$159(9.85)$

157 (9.72)

174 (I0.64)

Source: Authors' computation

Note: Percentages are reported in parenthesis

\section{Bivariate analysis of association between HIV test} uptake and socioeconomic variables

The bivariate analysis provides association between respondents' characteristics and whether or not they have ever tested for HIV/AIDS. The results show that a majority of respondents who know a place to test for HIV/AIDS have never tested. The chi-square test result showed that this association was statistically significant at $1 \%$ level for both men and women.

The association between HIV test uptake and stigma behaviour was similar for all the measures of HIV-related stigma. Majority of respondents who were more inclined to stigmatize against relatives with HIV/AIDS had never been tested. For instance, about $72.9 \%$ of female respondents who were not willing to care for relatives with HIV/AIDS had never 
been tested. Similar association was established for male respondents and across the different measures of HIV-related stigma. In terms of the association between sexual behaviour and HIV test uptake, both men and women who did not use condoms at their last sexual activity had never tested for HIV. The relationship was significant at $1 \%$ level. Similarly, majority of respondents who consumed alcohol during their last sexual activity had never tested for HIV/AIDS. The relationship was also significant at I\% statistical level.

The association established between other socioeconomic variables and HIV test uptake also showed that majority of respondents from both rural and urban areas had never tested for HIV/AIDS. The association was consistent for both men and women and was significant at $1 \%$ level. Also, HIV test uptake was highest among men and women from wealthier households and lowest among respondents from poorest households. HIV/AIDS test uptake increased with higher levels of education among both male and female respondents. For instance, while about $80.8 \%$ of females with no formal education had ever tested for HIV/AIDS, about $58 \%$ of women with postsecondary education had never tested for HIV/AIDS. Women who had no formal education were less likely to test for HIV. On the contrary, women with secondary and post-secondary education were more likely to have ever taken HIV test. The result is similar for men with secondary education. The relationship was significant at $1 \%$ for women and $5 \%$ for men. HIV test uptake was higher among Christians compared to respondents from other religious affiliations (i.e. Muslims and Traditionalists). Respondents with no religious affiliation had the lowest frequency of HIV test uptake. In terms of administrative regions, respondents from the Greater Accra and Ashanti regions had the highest frequency of HIV test uptake while those from the Central region had the lowest. 
Table 3: Bivariate analysis of HIV/AIDS test uptake and socioeconomic characteristics

\begin{tabular}{|c|c|c|c|c|c|c|}
\hline \multirow[t]{3}{*}{ Variable } & \multicolumn{3}{|c|}{ Female } & \multicolumn{3}{|c|}{ Male } \\
\hline & \multicolumn{3}{|c|}{ Ever tested for HIV/AIDS } & \multicolumn{3}{|c|}{ Ever tested for HIV/AIDS } \\
\hline & No $(\mathbf{N}=1 / 98)$ & Yes $(\mathbf{N}=425)$ & Chi-square & No $(N=|4| 2)$ & Yes $(\mathbf{N}=\mathbf{2 8 6})$ & Chi-square \\
\hline \multicolumn{7}{|c|}{ HIV/AIDS knowledge } \\
\hline \multicolumn{7}{|c|}{ Know a place to get AIDS test } \\
\hline No & $498(100.00)$ & $0(0.00)$ & \multirow{2}{*}{$254.88 * * *$} & $397(100.00)$ & $0(0.00)$ & \multirow{2}{*}{$104.95 * * *$} \\
\hline Yes & $700(62.22)$ & $425(37.78)$ & & $1015(78.02)$ & $286(21.98)$ & \\
\hline \multicolumn{7}{|c|}{ Ever heard of AIDS } \\
\hline \multicolumn{7}{|c|}{ No } \\
\hline Yes & I I $98(73.81)$ & $425(26.19)$ & & $1412(83.16)$ & $286(16.84)$ & \\
\hline \multicolumn{7}{|c|}{ Perceived HIV-related Stigmatization and discrimination } \\
\hline \multicolumn{7}{|c|}{ Willing to care for relative with AIDS } \\
\hline No & $288(72.91)$ & $107(27.09)$ & \multirow{2}{*}{6.02} & $268(86.73)$ & $4 I(13.27)$ & \multirow{2}{*}{5.36} \\
\hline Yes & $893(74.17)$ & $3 \mid I(25.83)$ & & $1120(82.17)$ & $243(17.83)$ & \\
\hline \multicolumn{7}{|c|}{ Person with AIDS allowed to continue teaching } \\
\hline No & $465(76.99)$ & $139(23.01)$ & \multirow{2}{*}{ II.50*** } & $505(87.07)$ & $75(12.93)$ & \multirow{2}{*}{$9.88 * *$} \\
\hline Yes & $703(71.30)$ & $283(28.70)$ & & $876(81.11)$ & 204(I8.89) & \\
\hline \multicolumn{7}{|c|}{ Would buy vegetables from vendor with AIDS } \\
\hline No & $900(75.82)$ & $287(24.18)$ & \multirow{2}{*}{$12.68 * * *$} & $877(86.49)$ & $137(13.51)$ & \multirow{2}{*}{$22.64 * * *$} \\
\hline Yes & $287(67.69)$ & $137(32.31)$ & & $515(77.79)$ & $147(22.21)$ & \\
\hline \multicolumn{7}{|c|}{ Risky sexual activities } \\
\hline \multicolumn{7}{|c|}{ Used condom at last intercourse } \\
\hline No & $1076(74.67)$ & $365(25.33)$ & \multirow{2}{*}{$8.21 * * *$} & $123 \mid(84.14)$ & $232(15.86)$ & \multirow{2}{*}{$7.69 * * *$} \\
\hline Yes & $27(56.25)$ & $21(43.75)$ & & $90(74.38)$ & $31(25.62)$ & \\
\hline \multicolumn{7}{|c|}{ Consumed alcohol last time had sex } \\
\hline No & $996(73.45)$ & $360(26.55)$ & \multirow{2}{*}{$3.09 *$} & $1185(83.16)$ & $240(16.84)$ & \\
\hline Yes & $107(80.45)$ & $26(19.55)$ & & $136(85.53)$ & $23(14.47)$ & 0.58 \\
\hline Partner ha & & & & & & \\
\hline No & $974(72.20)$ & $375(27.80)$ & & & & \\
\hline Yes & $224(81.75)$ & $50(18.25)$ & & S小a & & \\
\hline Responde & & & & & & \\
\hline No & $119(68.00)$ & $56(32.00)$ & & $22(73.33)$ & $8(26.67)$ & \\
\hline Yes & $1079(74.52)$ & $369(25.48)$ & $3.43^{*}$ & $1390(83.33)$ & $278(16.67)$ & 2.1 \\
\hline Type of $p$ & & & & & & \\
\hline Rural & 808 (78.98) & $215(21.02)$ & & $964(88.52)$ & $125(1 \mathrm{l} .48)$ & \\
\hline Urban & $390(65.00)$ & $210(35.00)$ & $38.26^{* 2 * 3}$ & $448(73.56)$ & I6I (26.44) & 62.40 称 \\
\hline Wealth Ir & & & & & & \\
\hline Poorest & $363(80.49)$ & $88(19.5 I)$ & $66.81 * * * *$ & 453 (9I.70) & $4 I(8.30)$ & $103.56 * * *$ \\
\hline
\end{tabular}




\begin{tabular}{|c|c|c|c|c|c|c|}
\hline Poor & 275 (83.08) & $56(16.92)$ & & $312(90.17)$ & $34(9.83)$ & \\
\hline Middle & $185(76.13)$ & $58(23.87)$ & & $206(82.40)$ & $44(17.60)$ & \\
\hline Rich & $196(65.77)$ & $102(34.23)$ & & 240 (78.69) & $65(21.31)$ & \\
\hline Richest & 179 (59.67) & $|2|(40.33)$ & & $201(66.34)$ & $102(33.66)$ & \\
\hline \multicolumn{7}{|l|}{ Age group } \\
\hline $15-19$ & $32(72.73)$ & $12(27.27)$ & \multirow{9}{*}{$49.76 * * * *$} & $4(100.00)$ & $0 .(0.00)$ & \multirow{9}{*}{$16.87 * *$} \\
\hline $20-24$ & $180(72.58)$ & $68(27.42)$ & & $60(85.71)$ & $10(14.29)$ & \\
\hline $25-29$ & $230(65.34)$ & $122(34.66)$ & & $172(81.90)$ & $38(18.10)$ & \\
\hline $30-34$ & $224(69.78)$ & $97(30.22)$ & & $240(80.27)$ & $59(19.73)$ & \\
\hline $35-39$ & $217(73.56)$ & 78 (26.44) & & $258(79.88)$ & $65(20.12)$ & \\
\hline $40-44$ & $170(83.74)$ & $33(16.26)$ & & $221(80.95)$ & $52(19.05)$ & \\
\hline $45-49$ & 145 (90.63) & $15(9.38)$ & & $222(89.16)$ & $27(10.84)$ & \\
\hline $50-54$ & & & & I 63 (88.59) & $2 I(I I .4 I)$ & \\
\hline $55-59$ & & & & 72 (83.72) & $14(16.28)$ & \\
\hline \multicolumn{7}{|c|}{ Highest educational level of respondent } \\
\hline No education & $489(80.83)$ & $116(19.17)$ & \multirow{4}{*}{$44.76 * * *$} & $432(91.72)$ & $39(8.28)$ & \multirow{4}{*}{$83.894 * *$} \\
\hline Primary & $271(77.43)$ & $79(22.57)$ & & $197(90.37)$ & $21(9.63)$ & \\
\hline Secondary & $409(66.50)$ & $206(33.50)$ & & $700(80.09)$ & $174(19.91)$ & \\
\hline Higher & $29(58.72)$ & $24(45.28)$ & & $83(61.48)$ & $52(38.52)$ & \\
\hline \multicolumn{7}{|l|}{ Religious affiliation } \\
\hline No religion & $49(84.48)$ & $9(15.52)$ & \multirow{4}{*}{ |4.88*** } & $97(95.10)$ & $5(4.90)$ & \multirow{4}{*}{$15.28 * * *$} \\
\hline Christian & $788(71.77)$ & $310(28.23)$ & & $828(81.34)$ & $190(18.66)$ & \\
\hline Muslim & $203(72.24)$ & $78(27.76)$ & & $266(82.35)$ & $57(17.65)$ & \\
\hline Traditional/Spiritual & $107(85.60)$ & $18(14.40)$ & & $160(87.43)$ & $23(12.57)$ & \\
\hline \multicolumn{7}{|l|}{ Administrative regions } \\
\hline Western & 135 (82.82) & $28(17.18)$ & \multirow{10}{*}{$50.43 * * *$} & I 57 (88.20) & $21(11.80)$ & \multirow{10}{*}{$45.00 * * *$} \\
\hline Central & $66(77.65)$ & $19(22.35)$ & & $70(84.34)$ & $13(15.66)$ & \\
\hline Greater Accra & $116(61.05)$ & $74(38.95)$ & & $122(68.93)$ & $55(31.07)$ & \\
\hline Volta & $110(80.88)$ & $26(1912)$ & & I3I (89.73) & $15(10.27)$ & \\
\hline Eastern & $123(76.40)$ & $38(23.60)$ & & $139(89.10)$ & $17(10.90)$ & \\
\hline Ashanti & I $47(70.33)$ & $62(29.67)$ & & I 73 (78.64) & $47(21.36)$ & \\
\hline Brong Ahafo & $81(60.90)$ & $52(39.10)$ & & $110(81.48)$ & $25(18.52)$ & \\
\hline Northern & $|5|(81.62)$ & $34(18.38)$ & & $177(86.76)$ & $27(13.24)$ & \\
\hline Upper East & $123(77.85)$ & $35(22.15)$ & & $122(79.74)$ & $31(20.26)$ & \\
\hline Upper West & $95(66.90)$ & $47(33.10)$ & & $150(86.21)$ & $24(13.79)$ & \\
\hline
\end{tabular}

Source: Authors' computation

Note: Percentages are reported in parenthesis. ***significant at 1\%; **significant at 5\%; *significant at $10 \%$ 


\section{Determinants of HIV-related stigma}

Table 4 and 5 presents logistic results from the multivariate analysis of the determinants of HIV-related stigma. Three different dependent variables were used to measure respondents inclination to stigmatize.

The results from Table 4 show that men from urban areas were more likely to stigmatize, relative to their counterparts from rural areas. This result was only significant for model I $(O R=0.59$; $\mathrm{Cl}=0.40-0.88)$. The result also showed that men from the wealthiest households were less inclined to stigmatize, relative to their counterparts from the poorest households. This association was consistent for all the models. The relationship was also significant at $5 \%$ for Model I with $\mathrm{OR}=3.65$ and
$\mathrm{Cl}=1.83-7.92, \quad \mathrm{I} \%$ for Model $2 \quad(\mathrm{OR}=3.07$; $\mathrm{Cl}=\mathrm{I} .72-5.48)$ and $\mathrm{I} \%$ for Model $3(\mathrm{OR}=2.57$; $\mathrm{Cl}=\mathrm{I} .52-4.35)$.

Men with higher education (above secondary level) were associated with decreased odds of exhibiting HIV-related stigma behaviours with $\mathrm{OR}=$ 2.65 for Model I $(\mathrm{Cl}=1.29-5.45), \mathrm{OR}=4.49$ for Model $2(\mathrm{Cl}=2.32-8.70)$ and $\mathrm{OR}=4.07$ for Model 3 $(\mathrm{Cl}=2.39-6.94)$. Men who were employed were more likely to exhibit HIV related stigma behaviour. The relationship was only significant for Model I $(\mathrm{OR}=0.14 ; \mathrm{Cl}=0.02-\mathrm{I} .12)$. Also, men with some religious affiliation were associated with decreased odds of stigmatizing. The relationship was only significant in the first model.

Table 4: Logistic regression Odds Ratios representing the Likelihood of expressing HIV-related stigma in Ghana (Males)

\begin{tabular}{|c|c|c|c|c|c|c|}
\hline \multirow{2}{*}{ Variable } & \multicolumn{2}{|c|}{ Model I } & \multicolumn{2}{|c|}{ Model 2} & \multicolumn{2}{|c|}{ Model 3} \\
\hline & Odds Ratio & $\begin{array}{c}\text { Confidence } \\
\text { Interval }\end{array}$ & $\begin{array}{l}\text { Odds } \\
\text { Ratio }\end{array}$ & $\begin{array}{c}\text { Confidence } \\
\text { Interval }\end{array}$ & $\begin{array}{l}\text { Odds } \\
\text { Ratio }\end{array}$ & $\begin{array}{c}\text { Confidence } \\
\text { Interval }\end{array}$ \\
\hline \multicolumn{7}{|c|}{ Type of place of residence } \\
\hline Rural & $\mathrm{RC}$ & & $\mathrm{RC}$ & & $\mathrm{RC}$ & \\
\hline Urban & $0.59 * * *$ & $0.40-0.88$ & 1.07 & $0.76-|.5|$ & 1.2 & $0.88-1.65$ \\
\hline \multicolumn{7}{|c|}{ Wealth Index Quintile } \\
\hline Poorest & $\mathrm{RC}$ & & & & & \\
\hline Poor & I.78*** & $1.16-2.73$ & $\mathrm{I} .07$ & $0.77-1.49$ & 1.21 & $0.85-I .74$ \\
\hline Middle & $|.5|$ & $0.92-2.46$ & $1.46 *$ & $0.96-2.21$ & $1.66 * *$ & $1.11-2.50$ \\
\hline Rich & $2.24 * * *$ & $1.28-3.92$ & $2.2 I^{* * * *}$ & $1.39-3.52$ & $2.49 * * *$ & $1.61-3.87$ \\
\hline Richest & $3.65 * *$ & $1.83-7.92$ & $3.07 * * *$ & I.72-5.48 & $2.57 * * *$ & $\mathrm{I} .52-4.35$ \\
\hline \multicolumn{7}{|c|}{ Highest Educational level of respondent } \\
\hline No education & RC & & RC & & $\mathrm{RC}$ & \\
\hline Primary & 1.22 & $0.75-1.99$ & $1.46 *$ & $1.00-2.15$ & I.49** & $1.00-2.22$ \\
\hline Secondary & 1.25 & $0.82-1.89$ & I.74*** & $1.23-2.46$ & $1.90 * * *$ & $1.32-2.73$ \\
\hline Higher & $2.65 * * *$ & I.29-5.45 & $4.49 * * *$ & $2.32-8.70$ & $4.07 * * *$ & $2.39-6.94$ \\
\hline \multicolumn{7}{|c|}{ Respondent currently working } \\
\hline No & $\mathrm{RC}$ & & $\mathrm{RC}$ & & $\mathrm{RC}$ & \\
\hline Yes & $0.14 *$ & $0.02-1.12$ & 0.82 & $0.30-2.19$ & 1.81 & $0.74-4.44$ \\
\hline \multicolumn{7}{|c|}{ Religious affiliation of respondent } \\
\hline No religion & $\mathrm{RC}$ & & $\mathrm{RC}$ & & $\mathrm{RC}$ & \\
\hline Christian & $1.60 *$ & $0.98-2.62$ & 1.13 & $0.72-1.75$ & $1.73 * *$ & $|.06-2.8|$ \\
\hline Muslim & $1.96 * *$ & $1.08-3.55$ & 0.74 & $0.45-1.23$ & 1.57 & $0.90-2.70$ \\
\hline Traditional/Spiritual & 1.54 & $0.78-3.06$ & 0.67 & $0.39-1.17$ & 1.34 & $0.72-2.48$ \\
\hline Age & I & $0.99-1.02$ & 1.01 & $1.00-1.02$ & 1.01 & $1.00-1.02$ \\
\hline \multicolumn{7}{|c|}{ Administrative regions } \\
\hline Western & $\mathrm{RC}$ & & $\mathrm{RC}$ & & $\mathrm{RC}$ & \\
\hline Central & 0.62 & $0.34-1.12$ & 1.12 & $0.63-1.98$ & 1.25 & $0.7 I-2.18$ \\
\hline Greater Accra & 0.77 & $0.43-1.37$ & 0.95 & $0.55-1.64$ & 0.96 & $0.59-1.57$ \\
\hline Volta & $2.4 I * * *$ & $1.32-4.39$ & 0.95 & $0.60-1.52$ & $2.33^{* * * *}$ & $1.44-3.76$ \\
\hline Eastern & 0.86 & $0.52-1.43$ & 0.88 & $0.55-1.42$ & 1.11 & $0.70-1.78$ \\
\hline Ashanti & $1.63^{*}$ & $0.97-2.74$ & $1.58 * *$ & $1.00-2.50$ & 0.74 & $0.48-1.14$ \\
\hline
\end{tabular}




\begin{tabular}{lcccccc} 
Brong Ahafo & $2.46 * * *$ & $1.33-4.56$ & 0.97 & $0.59-1.60$ & $1.76 * *$ & $1.06-2.92$ \\
Northern & $1.73^{*}$ & $0.94-3.18$ & $1.83 * *$ & $1.09-3.08$ & 0.72 & $0.42-1.23$ \\
Upper East & $4.87^{* * *}$ & $2.35-10.10$ & $1.98 * * *$ & $1.18-3.33$ & $2.11 * * *$ & $1.23-3.61$ \\
Upper West & $7.65 * * *$ & $3.33-17.56$ & $5.91 * * *$ & $3.36-10.40$ & 1.09 & $0.65-1.83$ \\
\hline
\end{tabular}

Source: Authors' computation

Notes:

***significant at 1\%; **significant at $5 \%$; *significant at $10 \%$

Model I dependent variable is willing to take care of a relative with AIDS

Model 2 dependent variable is person with AIDS should be allowed to continue teaching

Model 3 dependent variable is willing to buy from a vendor with AIDS

$\mathrm{OR}=$ Odds Ratio; $\mathrm{Cl}=$ Confidence Interval

Results from the analysis for female respondents showed that living in rural locations $(\mathrm{OR}=1.37 ; \mathrm{Cl}=$ $0.95-1.99$ ), belonging to a religions group and being older $(\mathrm{OR}=1.02 ; \mathrm{Cl}=1.00-\mathrm{I} .03)$ were significantly associated with low HIV-related stigma behaviour. On the contrary, women from wealthier households (richest wealth quintile category) were associated with higher HIV-related stigma, relative to women from the poorest households.

In the second model, above secondary level education (OR=14.0I; $\mathrm{Cl}=3.28-59.82)$ and being a Muslim (OR= 2.22; $\mathrm{Cl}=1.18-4.18)$ were significant- ly associated with low level of stigma related behaviour. Primary level of education was associated with increased odds of stigmatization $(\mathrm{OR}=0.90 ; \mathrm{Cl}=$ 0.66-I.25). In the third model, women from the richest households $(\mathrm{OR}=2.08 ; \mathrm{Cl}=1.18-3.69)$, primary level of education $(\mathrm{OR}=\mathrm{I} .7 ; \mathrm{Cl}=\mathrm{I} .18$ 2.44), secondary level of education $(\mathrm{OR}=1.65 ; \mathrm{Cl}=$ I.14-2.39) and higher education $(\mathrm{OR}=7.84 ; \mathrm{Cl}=$ 3.70-16.59) were less inclined to stigmatize. Women affiliated to traditional/spiritual religions were more inclined to stigmatize, relative to their counterparts without any religious affiliation.

Table 5: Logistic regression Odds Ratios representing the Likelihood of expressing HIV-related stigma in Ghana (Females)

\begin{tabular}{|c|c|c|c|c|c|c|}
\hline \multirow{2}{*}{ Variable } & \multicolumn{2}{|c|}{ Model I } & \multicolumn{2}{|c|}{ Model 2} & \multicolumn{2}{|c|}{ Model 3} \\
\hline & $\begin{array}{l}\text { Odds } \\
\text { Ratio }\end{array}$ & $\begin{array}{c}\text { Confidence } \\
\text { Interval }\end{array}$ & $\begin{array}{l}\text { Odds } \\
\text { Ratio }\end{array}$ & $\begin{array}{c}\text { Confidence } \\
\text { Interval }\end{array}$ & $\begin{array}{l}\text { Odds } \\
\text { Ratio }\end{array}$ & $\begin{array}{c}\text { Confidence } \\
\text { Interval }\end{array}$ \\
\hline \multicolumn{7}{|c|}{ Type of place of residence } \\
\hline Rural & $\mathrm{RC}$ & & $\mathrm{RC}$ & & & \\
\hline Urban & $1.37 *$ & $0.95-1.99$ & 1.23 & $0.89-1.70$ & I & $0.69-1.43$ \\
\hline \multicolumn{7}{|l|}{ Wealth Index } \\
\hline \multicolumn{7}{|l|}{ Quintile } \\
\hline Poorest & $\mathrm{RC}$ & & $\mathrm{RC}$ & & & \\
\hline Poor & 0.9 & $0.6|-| .3 \mid$ & 1.2 & $0.85-1.69$ & 0.99 & $0.66-1.48$ \\
\hline Middle & 1.28 & $0.8 \mathrm{I}-2.02$ & 1.32 & $0.88-1.96$ & 1.2 & $0.76-1.90$ \\
\hline Rich & 1.12 & $0.69-|.8|$ & $2.13^{* * * *}$ & $1.39-3.29$ & I.88** & $1.16-3.06$ \\
\hline Richest & 0.9 & $0.50-1.62$ & $1.78 * *$ & $\mathrm{I} .05-3.0 \mathrm{I}$ & $2.08^{* *}$ & $1.18-3.69$ \\
\hline \multicolumn{7}{|c|}{ Highest Educational level of respondent } \\
\hline No education & RC & & $\mathrm{RC}$ & & $\mathrm{RC}$ & \\
\hline Primary & I & $0.7 I-1.42$ & $0.90 *$ & $0.66-1.25$ & $1.7^{* * *}$ & I.18-2.44 \\
\hline Secondary & $\mathrm{I} .5 \mathrm{I} * *$ & $1.06-2.15$ & I.49** & I.08-2.07 & $1.65^{* * * *}$ & I.14-2.39 \\
\hline Higher & 1.97 & $0.87-4.47$ & $|4.0| * * *$ & $3.28-59.82$ & $7.84 * * *$ & $3.70-16.59$ \\
\hline \multicolumn{7}{|c|}{ Respondent currently working } \\
\hline No & $\mathrm{RC}$ & & $\mathrm{RC}$ & & $\mathrm{RC}$ & \\
\hline Yes & 1.37 & $0.93-2.02$ & 1.03 & $0.7 I-1.50$ & 1.05 & $0.77-1.73$ \\
\hline \multicolumn{7}{|c|}{ Religious affiliation of respondent } \\
\hline No religion & $\mathrm{RC}$ & & $\mathrm{RC}$ & & $\mathrm{RC}$ & \\
\hline Christian & $1.60 *$ & $0.82-3.13$ & 1.4 & $0.79-2.47$ & 0.67 & $0.36-I .24$ \\
\hline Muslim & $1.63 *$ & $0.80-3.34$ & $2.22 * *$ & $1.18-4.18$ & 0.69 & $0.34-1.37$ \\
\hline $\begin{array}{l}\text { Tradition- } \\
\text { al/Spiritual }\end{array}$ & 1.28 & $0.58-2.83$ & 1.01 & $0.51-1.98$ & $0.15^{* * * *}$ & $0.06-0.38$ \\
\hline 1373 & & & & & & s.journals.a \\
\hline
\end{tabular}




\begin{tabular}{|c|c|c|c|c|c|c|}
\hline Age & $1.02 * *$ & I.00-I.03 & I & $0.99-1.02$ & 1.01 & $0.99-1.03$ \\
\hline \multicolumn{7}{|c|}{ Administrative regions } \\
\hline Western & $\mathrm{RC}$ & & & & & \\
\hline Central & $0.21 * * *$ & $0.12-0.40$ & 0.94 & $0.54-1.63$ & 0.62 & $0.32-1.23$ \\
\hline Greater Accra & $0.49 * *$ & $0.27-0.89$ & 1.12 & $0.66-1.88$ & $\mathrm{I} .04$ & $0.63-1.73$ \\
\hline Volta & 0.87 & $0.48-I .58$ & I.72*** & I.04-2.85 & I.74** & $1.03-2.96$ \\
\hline Eastern & $0.59 *$ & $0.34-1.03$ & 0.76 & $0.47-1.22$ & $0.45 * * *$ & $0.25-0.80$ \\
\hline Ashanti & $0.35^{* * * *}$ & $2.11-0.60$ & $0.67^{*}$ & $0.43-1.05$ & 0.98 & $0.61-0.56$ \\
\hline Brong Ahafo & 0.63 & $0.35-1.12$ & I.I & $0.67-1.81$ & 0.74 & $0.42-1.31$ \\
\hline Northern & 0.68 & $0.38-I .23$ & 0.97 & $0.57-1.66$ & 1.51 & $0.84-2.72$ \\
\hline Upper East & $3.37 * * *$ & I.60-7.07 & $6.67 * * *$ & $3.74-11.91$ & 1.42 & $0.8 I-2.5 I$ \\
\hline Upper West & $2.03 * *$ & $1.03-4.01$ & $3.22 * * *$ & I.85-5.59 & $2.4 I^{* * * *}$ & I.38-4.22 \\
\hline
\end{tabular}

Source: Authors' computation

\section{Notes:}

***significant at 1\%; **significant at $5 \%$; *significant at $10 \%$

Model I dependent variable is willing to take care of a relative with AIDS

Model 2 dependent variable is person with AIDS should be allowed to continue teaching

Model 3 dependent variable is willing to buy from a vendor with AIDS

$\mathrm{OR}=$ Odds Ratio; $\mathrm{Cl}=$ Confidence Interval

\section{Determinants of HIV test uptake in Ghana}

Tables 6 and 7 present logistic regression results from multivariate analysis of the determinants of HIV test uptake in Ghana. Two separate models were used in the analysis. The first model examines the effect of HIV-related stigma on HIV test uptake while the second model introduced socioeconomic variables, including sexual behaviour. The results for females presented in Table 6 show that in both Models I and 2, women from wealthier households were significantly associated with increased odds of HIV test uptake, relative to their counterparts from the poorest households. In model I, women with secondary level education were significantly associated with increased odds of HIV test uptake (OR=
I.57; $\mathrm{Cl}=1.09-2.27)$. Similar relationship was established in model 2 with $\mathrm{OR}=\mathrm{I} .60$ and $\mathrm{Cl}=|.| \mathrm{I}-2.3 \mathrm{I}$.

Also, in both models, women who used condoms during the last sexual activity were more likely to test for HIV while those who consumed alcohol during the last sexual activity were less likely to test for HIV. The relationships were statistically significant in both models. In terms of stigma related behaviour and HIV test uptake, the results from model I shows that women who were willing to take care of a relative with HIV/AIDS were less likely to test for HIV $(\mathrm{OR}=0.73 ; \mathrm{Cl}=0.54-\mathrm{I} .00)$. On the contrary, women who would buy from a vendor with HIV/AIDS were more likely to test for HIV (OR= $\mathrm{I} .34 ; \mathrm{Cl}=\mathrm{I} .00-\mathrm{I} .77)$. Both relationships were marginally significant.

Table 6: Logistic regression Odds Ratios representing the Likelihood of HIV-test uptake in Ghana (Female)

\begin{tabular}{|c|c|c|c|c|}
\hline \multirow[b]{2}{*}{ Variable } & \multicolumn{2}{|c|}{ Model I } & \multicolumn{2}{|c|}{ Model 2} \\
\hline & $\begin{array}{l}\text { Odds Ra- } \\
\text { tio }\end{array}$ & $\begin{array}{l}\text { Confidence Inter- } \\
\text { val }\end{array}$ & $\begin{array}{l}\text { Odds Ra- } \\
\text { tio }\end{array}$ & $\begin{array}{c}\text { Confidence Inter- } \\
\text { val }\end{array}$ \\
\hline \multicolumn{5}{|c|}{ Type of place of residence } \\
\hline Rural & $\mathrm{RC}$ & & $\mathrm{RC}$ & \\
\hline Urban & 0.96 & $0.66-1.38$ & 0.94 & $0.65-1.36$ \\
\hline \multicolumn{5}{|c|}{ Wealth Index Quintile } \\
\hline Poorest & $\mathrm{RC}$ & & $\mathrm{RC}$ & \\
\hline Poor & 0.81 & $0.53-1.25$ & 0.83 & $0.54-1.28$ \\
\hline Middle & 1.38 & $0.88-2.23$ & 1.4 & $0.87-2.25$ \\
\hline Rich & $1.92 * *$ & $1.16-3.16$ & $2.00 * * *$ & $1.22-3.29$ \\
\hline Richest & $2.37 * * * *$ & I.32-4.26 & $2.51 * * * *$ & $1.40-4.50$ \\
\hline \multicolumn{5}{|c|}{ Highest Educational level of respondent } \\
\hline No education & $\mathrm{RC}$ & & $\mathrm{RC}$ & \\
\hline Primary & 1.06 & $0.73-I .54$ & 1.09 & $0.75-1.59$ \\
\hline Secondary & $1.57 * *$ & $1.09-2.27$ & $1.60 * *$ & $||.|-2.3|$ \\
\hline
\end{tabular}


Perceived HIV-related Stigmatization and discrimination

Willing to care for relative with

aids

No RC

Yes 0.73*

$0.54-1.00$

Person with aids allowed to continue teaching

No RC

Yes $\quad 1.09$

$0.82-1.45$

Would buy vegetables from vendor with aids

No

RC

Yes I.34*

I.00-I.77

Risky sexual activities

Used condom at last intercourse

No RC

Yes I.93**

$1.01-3.69$

$\mathrm{RC}$

I.90*

$0.99-3.65$

Consumed alcohol last time had

sex

No

RC RC

Yes 0.73

Respondent currently working

$0.46-1.15 \quad 0.72 *$

$0.46-1.14$

No

RC RC

$\begin{array}{ll}\text { Yes } & 0.89\end{array}$

Administrative regions

Western

Central

RC

Greater Accra

$0.59-1.35$

0.89

$0.59-1.34$

Volta

I

$1.67 *$

$0.49-2.04$

RC

1.21

$0.95-2.93$

1.07

$0.53-2.16$

Eastern

1.52

$0.65-2.27$

1.73*

$0.99-3.03$

Ashanti

$1.75 * *$

$0.85-2.71$

1.26

$0.67-2.35$

Brong Ahafo

$3.5 * * *$

$1.02-2.98$

1.48

$0.83-2.63$

Northern

1.45

1.98-6.18

1.83**

1.08-3.09

Upper East

$0.76-2.75$

$3.52^{* * * *}$

2.00-6. 18

$2.3^{* *}$

I.2I-4.37

1.5

$0.80-2.84$

Upper West

3.37 ***

1.79-6.36

I. $22-4.28$

Source: Authors' computation

Notes:

***significant at I\%; **significant at $5 \%$; *significant at $10 \%$ Model I is model without HIV-related stigma variables Model 2 is model with HIV-related stigma variables

$\mathrm{OR}=$ Odds Ratio; $\mathrm{Cl}=$ Confidence Interval

The results for male respondents presented in Table 7 shows similar association between socioeconomic variables and HIV test uptake, as in the case of females. In both Models I and 2, men from wealthier households were associated with increased odds of HIV test uptake, relative to their counterparts from poorest households. Also men with secondary or higher levels of education were associated with increased odds of HIV test uptake, relative to their counterparts with no formal education. Also, men who used condoms during their last sexual activity were significantly more likely to test for HIV. The relationship was consistent for both models.

In terms of HIV-related stigma behaviour, a positive association was established with HIV test uptake, even though this relationship was not statistically significant. While men who were willing to take care of a relative with HIV/AIDS $(\mathrm{OR}=1.18 ; \mathrm{Cl}=$ 0.78-1.97) and willing to buy from a vendor with HIV/AIDS (OR $=1.25 ; \mathrm{Cl}=0.9 \mathrm{I}-\mathrm{I} .70)$ were associated with increased odds of HIV test uptake. 
Table 7: Logistic regression Odds Ratios representing the Likelihood of HIV-test uptake in Ghana (Male)

\begin{tabular}{|c|c|c|c|c|}
\hline \multirow[b]{2}{*}{ Variable } & \multicolumn{2}{|r|}{ Model I } & \multicolumn{2}{|r|}{ Model 2} \\
\hline & $\begin{array}{l}\text { Odds } \\
\text { Ratio }\end{array}$ & $\begin{array}{l}\text { Confidence Inter- } \\
\text { val }\end{array}$ & $\begin{array}{l}\text { Odds } \\
\text { Ratio }\end{array}$ & $\begin{array}{c}\text { Confidence Inter- } \\
\text { val }\end{array}$ \\
\hline \multicolumn{5}{|c|}{ Type of place of residence } \\
\hline Rural & $\mathrm{RC}$ & & $\mathrm{RC}$ & \\
\hline Urban & 1.19 & $0.79-1.78$ & 1.18 & $0.79-1.76$ \\
\hline \multicolumn{5}{|c|}{ Wealth Index Quintile } \\
\hline Poorest & $\mathrm{RC}$ & & $\mathrm{RC}$ & \\
\hline Poor & 1.57 & $0.89-2.77$ & 1.59 & $0.90-2.80$ \\
\hline Middle & $2.72 * * * *$ & $1.48-4.99$ & $2.74 * * *$ & $1.49-5.03$ \\
\hline Rich & $2.66 * * *$ & $1.43-4.93$ & $2.7 \mid * * *$ & $1.45-5.04$ \\
\hline Richest & 4. $10^{* * * *}$ & $2.03-8.30$ & $4.19 * * *$ & $2.07-8.50$ \\
\hline \multicolumn{5}{|c|}{$\begin{array}{l}\text { Highest Educational level of respond- } \\
\text { ent }\end{array}$} \\
\hline No education & $\mathrm{RC}$ & & $\mathrm{RC}$ & \\
\hline Primary & 0.87 & $0.45-1.69$ & 0.87 & $0.45-1.68$ \\
\hline Secondary & $2.09 * * *$ & $0.25-3.50$ & 2. || $1 * * *$ & I.27-3.50 \\
\hline Higher & $3.53^{* * * *}$ & $1.85-6.93$ & $3.64 * * *$ & $1.94-6.84$ \\
\hline \multicolumn{5}{|c|}{ Perceived HIV-related Stigmatization and discrimination } \\
\hline \multicolumn{5}{|c|}{ Willing to care for relative with aids } \\
\hline No & $\mathrm{RC}$ & & & \\
\hline Yes & 1.18 & $0.78-1.79$ & & \\
\hline \multicolumn{5}{|c|}{ Person with aids allowed to continue teaching } \\
\hline No & $\mathrm{RC}$ & & & \\
\hline Yes & 0.81 & $0.57-I .14$ & & \\
\hline \multicolumn{5}{|c|}{ Would buy vegetables from vendor with aids } \\
\hline No & $\mathrm{RC}$ & & & \\
\hline Yes & 1.25 & $0.91-1.70$ & & \\
\hline \multicolumn{5}{|c|}{ Risky sexual activities } \\
\hline \multicolumn{5}{|c|}{ Used condom at last intercourse } \\
\hline No & $\mathrm{RC}$ & & $\mathrm{RC}$ & \\
\hline Yes & 1.44 & $0.86-2.42$ & 1.44 & $0.86-2.42$ \\
\hline \multicolumn{5}{|c|}{ Consumed alcohol last time had sex } \\
\hline No & $\mathrm{RC}$ & & $\mathrm{RC}$ & \\
\hline Yes & 0.91 & $0.55-1.52$ & 0.93 & $0.56-1.54$ \\
\hline \multicolumn{5}{|c|}{ Employment status of respondent } \\
\hline \multicolumn{5}{|c|}{ Respondent currently working } \\
\hline No & $\mathrm{RC}$ & & $\mathrm{RC}$ & \\
\hline Yes & 107 & $0.40-2.90$ & 1.1 & $0.4 I-2.96$ \\
\hline \multicolumn{5}{|c|}{ Administrative regions } \\
\hline Western & $\mathrm{RC}$ & & $\mathrm{RC}$ & \\
\hline Central & 1.17 & $0.5 I-2.67$ & 1.17 & $0.5 I-2.66$ \\
\hline Greater Accra & $1.82 *$ & $0.98-3.36$ & $\mathrm{I} .8 \mathrm{I}^{*}$ & $0.98-3.35$ \\
\hline Volta & 1.01 & $0.49-2.06$ & 1.06 & $0.52-2.17$ \\
\hline Eastern & 0.96 & $0.48-1.92$ & 0.97 & $0.49-1.93$ \\
\hline Ashanti & $1.9 * *$ & $1.05-3.42$ & $1.86 * *$ & $1.03-3.34$ \\
\hline Brong Ahafo & $2.29 * *$ & I.17-4.47 & $2.4 I^{* * * *}$ & $|.24-4.7|$ \\
\hline Northern & $1.94 *$ & $0.95-3.95$ & $1.91 *$ & $0.94-3.89$ \\
\hline Upper East & $4.86^{* * * *}$ & $2.34-10.11$ & $5.06 * * *$ & $2.44-10.52$ \\
\hline Upper West & $2.76 * * *$ & $1.34-5.69$ & $2.69 * * *$ & I.32-5.49 \\
\hline
\end{tabular}

Source: Authors' computation 
Notes:

***significant at 1\%; **significant at 5\%; *significant at $10 \%$

Model I is model without HIV-related stigma variables

Model 2 is model with HIV-related stigma variables

$\mathrm{OR}=$ Odds Ratio; $\mathrm{Cl}=$ Confidence Interval

\section{Discussions}

The findings from the univariate analysis suggest that HIV test uptake remain significantly low in Ghana. This finding was not expected considering efforts made by the Ghana AIDS Commission to improve HIV test uptake through effective campaign and accessibility of test facilities. These efforts were evident from the high proportion of respondents who had ever heard of HIVIAIDS and know a place to test for the disease. The low test uptake may be attributed to "fear of HIV-related stigma and discrimination and fear of knowing status" as found by Ulasi et al (2009) in a study conducted in Ghana. Furthermore, the findings show that though more males know a place to get AIDS tests conducted, more females have ever been tested. While Asante (2013) found higher test uptake among males, the current study used nationally representative sample. Asante (2013) was only limited to students in a private university. This finding is not surprising because, though knowledge is an antecedent of action, it does not always lead to action. Thus, whereas more males know where to get tested, they actually do not get tested as much as females. This may be due to the idea that females are more ready to know their status and take precaution. However, it may also be due to the fact that once pregnant, females undergo testing (sometimes not having a choice not to).

While some evidence was found to confirm the prevalence of HIV-related stigma in Ghana, the level of respondents' inclination to stigmatize depends on the situation involved. Most male and female respondents were inclined to stigmatize against a vendor with AIDS compared to their relatives who were living with the disease. This finding may be justified in the case of Ghana, like in many other countries in sub-Sahara Africa, where family ties are stronger and held in high esteem.

The study also provided evidence to show that socioeconomic characteristics of individuals (both males and females) play an important role in HIV test uptake in Ghana. The bivariate and multivariate analyses suggested that household wealth status, education level of individuals and religious affiliation were significant determinants of HIV test uptake in Ghana. Specifically, the findings on wealth status suggest that both men and women from wealthier households were associated with increased odds of HIV test uptake. This finding conforms with existing studies (Gage and Ali, 2005, Glick and Sahn, 2007) and theoretical propositions that, in general, wealth is positively related to affordability, access and demand for health care. A critical policy effort should be directed towards reducing costs for poor and, especially, vulnerable population.

The finding on HIV test uptake and education was also consisted with expectations and for both males and females. Respondents with, at least, secondary level education were more likely to test for HIV, relative to their counterparts without any formal education. This finding is intuitively appealing as more educated individuals are expected to be conscious about their health status and demand health care. They also have a wider platform for knowledge acquisition on issues of HIV testing, stigmatization and sexual behaviour change practices.

A marginally significant and positive relationship was established between sexual behaviour and HIV test uptake. Respondents who did not use condoms were less likely to test for HIV. This finding contradicts earlier findings by Koku (20II) who found that engagement in risky sexual behaviour was associated with desire for HIV test uptake. Respondents who did not use condoms were expected to be more willing to test for HIV. This may be explained by the speculation that individuals are more willing to test for HIV when they are confident of not engaged in any risky activity. Individuals who engage in risky activities may prefer to be oblivious about their status. For instance Myerson (2012) found that only $3.6 \%$ of HIV negative men who had previously never used condoms desired for HIV test uptake in India.

With regards to HIV-related stigma, significant association with HIV test uptake was established for females but not males. Two separate results were established from different stigma variables. Individuals who were willing to take care of a relative with HIV/AIDS were less likely to test for HIV while those who were willing to buy from a vendor with HIV/AIDS were more likely to test for HIV. The former suggests that individuals who were less inclined to stigmatize were less likely to test for HIV. On the contrary, the later suggests that individuals who were less inclined to stigmatize were more 
likely to test for HIV. As noted by Koku (20II) and confirmed from the univariate analysis of this study, HIV-related stigma is prevalent in Ghana. However, the extent to which this affects HIV test uptake depends on the level of stigmatization and scenario involved.

The study also established some significant association between HIV-related stigma and socioeconomic characteristics of individuals. The findings suggest that, in general, individuals from rural areas, wealthier households, higher levels of education and those who were affiliated to some religious group were less likely to stigmatize. While these associations were expected, individuals from urban areas were expected to be less inclined to stigmatize, relative to rural residents considering the, relatively, high level of civilization. The contrary relationship established in this study may however be justified by the fact that HIV campaigns in Ghana have focused on rural communities in recent times. The positive association with religious affiliation was not surprising as both Christians and Muslims hold high moral values in showing love and support for community members.

\section{Conclusion}

The study examined the relationship between HIV test uptake and socioeconomic characteristics of individuals, including HIV-related stigma behaviours. The study also investigated the determinants of HIVrelated stigma behaviours in Ghana. Analysis was conducted using univariate, bivariate and multivariate models. Data from the $2008 \mathrm{GDHS}$ was employed in the analysis with cross-tabulations, chisquare tests and logistic regression techniques used.

The findings of the study suggest that HIV test uptake was significantly low among males and females in Ghana, despite high knowledge of the disease. The study also showed that socioeconomic characteristics such as household wealth status, education levels and religious affiliation were important determinants of HIV test uptake in Ghana. While evidence was found that HIV-related stigma is persistent in Ghana, strong but inconsistent association was also established between HIV-related stigma and HIV test uptake. The direction of association depended on the variable employed as measure of stigma. In terms of the determinants of HIV-related stigma, education, wealth status, rural place of residence and religious affiliation were also identified to be relevant.
The findings emphasises the call for zero complacency in the fight against HIV and HIV-related stigma behaviours. Improving comprehensive knowledge about HIV may be important for reducing stigma and improving test uptake. This implies that education should go beyond making people hear about HIV to understanding the transmission, prevention and care. Further, there is need for relentless effort to be made to improve accessibility and affordability of HIV test uptake. This requires such efforts as frequent community level free counselling and testing campaigns so as to encourage people to participate. Effective enactment and implementation of legislations that discourage HIV-related stigma behaviours may also be a crucial step in the right direction.

\section{Competing interest}

The authors declare they have no competing interests.

\section{Authors' contribution}

$J N(I)$ and $J N(2)$ conceived the study, $J N(I), J N(2)$, $\mathrm{NN}$ and GA undertook analysis and contributed to the write-up of the manuscript. All authors read and approved the final manuscript.

\section{References}

Ankomah, A. (1998) 'Condom use in sexual exchange relationships among young single adults in Ghana', AIDS Education and Prevention, 10, 303316.

Armah-Attoh, W. N.-O. (2009) Review of HIV counselling and testing related stigma in Ghana, unpublished thesis Vrij Universiteit Amsterdam.

Asante, O. K. (2013) 'HIV/AIDS knowledge and uptake of HIV counselling and testing among undergraduate private university students in Accra, Ghana', Reproductive Health, I0(17), I-8.

Awusabo-Asare, K. and C. Marfo (1997) 'Attitudes to the management of HIV/AIDS amoung health workers in Ghana: the case of Cape Coast Municipality', Health Transition Review, 7, 27I-280.

Ayenew, A., A. Leykun, R. Colebunders and A. Deribew (2010) 'Predictors of Hlv testing among patients with Tuberculosis in North West Ethiopia: A case-control study', PLoS ONE, 5(3).

Gage, A. J. and D. Ali (2005) 'Factors associated with self-reported HIV testing among men in Uganda', AIDS Care, 17, 153-165.

Ghana AIDS Commission (20I3) HIV sentinel survey report, Accra: Ghana AIDS Commission. 
Ghana Statistical Service (2008) Ghana demographic and health survey data Accra: Ghana Statistical Service.

Glick, P. and D. E. Sahn (2007) 'Changes in HIV/AIDS knowledge and testing behaviour in Africa: how much and for whom?', Journal of Population Economics, 20, 383-422.

Goffman, E. (1963) Stigma: Notes on the management of spoiled identity., New York: Simon and Schuster.

Helleringer, S., H.-P. Kohler, J. A. Frimpong and J. R. N. Mkandawire (2009) 'Increased uptake of HIV testing and counselling among the poorest in subSaharan countries through home-based service provision', Journal of Acquired Immune Deficiency Syndromes, 5 I (2), I85-193.

Koku, F. E. (20II) 'Stigma, sexual behaviour and desire for HIV test in Ghana', Sexual Health, 8, II0-II9.

Maughan-Brown, B. and L. Nyblade (2013) 'The effects of different dimensions of HIV-related stigma on HIV testing uptake among young men and women in Cape Town, South AFrica', Southern Africa Labour and Development Research Unit Working Paper Series No. 109.
Mill, J. (2003) 'Shrouded in secrecy: breaking the news of HIV infection to Ghanaian women ', Journal of Transcultural Nursing, 14, 6.16.

Myerson, R., M. S. Makela, C. Chandrasekhar, S. Mathew and S. Chakraborty (20I2) 'Determinants of condom uptake among HIV voluntary counselling and testing clients: experiences from a hospital-based study in south India ', BMC Health Services Research, 12(13).

Sambisa, W. (2008) 'AIDS stigma and uptake of HIV testing in Zimbabwe', Demographic and Health Survey Working Paper Series No. 49.

Ulasi, I. C., O. P. Preko, A. J. Baidoo, B. Bayard, E. J. Ehiri, M. C. Jolly and E. P. Jolly (2009) 'HIV/AIDSrelated stigma in Kumasi, Ghana', Health and Place, 15, 255-262.

WHO (2004) Report on the global AIDS epidemic, Geneva: World Health Organization.

Wong, L. P. (2013) 'Multi-ethnic Perspective of uptake of HIV testing and HIV-related stigma: a cross-sectional population-based study', AIDS Care, 25(II). 